\title{
Infliximab therapy in patients with ankylosing spondylitis: an open label 12 month study
}

T I Temekonidis, Y Alamanos, S N Nikas, D V Bougias, A N Georgiadis, P V Voulgari, A A Drosos

Ann Rheum Dis 2003;62:1218-1220. doi: 10.1136/ard.2003.014258

Objective: To evaluate the efficacy and safety of long term infliximab therapy in patients with severe refractory ankylosing spondylitis (AS).

Patients and methods: Twenty five patients (24 male, 1 female; mean (SD) age 36.0 (10.5); disease duration 13.8 (8.5) years) with AS fulfilling the modified New York criteria for AS were investigated. Twenty two (88\%) patients were HLA-B27 positive. All patients had active axial disease (Bath Ankylosing Spondylitis Disease Activity Index (BASDAI) $\geqslant 30 / 100$ ) and $C$ reactive protein (CRP) $\geqslant 10 \mathrm{mg} / \mathrm{l}$, despite adequate treatment. Intravenous infliximab $(5 \mathrm{mg} / \mathrm{kg})$ was given at weeks $0,2,6$, and every eight weeks thereafter for 12 months. The primary end point was the reduction of the patient's global assessment of pain (GAP) by $>20 \%$ on a $100 \mathrm{~mm}$ visual analogue scale.

Results: GAP was reduced by $>20 \%$ in $23(92 \%)$ patients, by $50 \%$ in $21(84 \%)$ patients, and by $70 \%$ in $13(52 \%)$. The change in BASDAI and CRP from baseline was statistically significant. The treatment was well tolerated with minimal side effects. One patient dropped out owing to inefficacy and one stopped treatment owing to an allergic reaction.

Conclusion: This longer length study confirms the efficacy of infliximab and the good safety profile in patients with AS.

A nkylosing spondylitis (AS) is the most common and the most typical form of spondyloarthropathy. It affects primarily the axial skeleton and it is often associated with peripheral synovitis and the presence of extra-articular manifestations. ${ }^{1}$ The use of non-steroidal antiinflammatory drugs (NSAIDs) at full therapeutic doses and a lifelong programme of regular exercise form the mainstay of management of AS. The use of disease modifying antirheumatic drugs (DMARDs), mainly sulfasalazine (SSZ) and methotrexate (MTX), may be useful in some patients. ${ }^{12}$

Recent studies demonstrated that antitumour necrosis factor $\alpha$ therapy (infliximab) is effective in patients with AS. Indeed, open label and randomised double blind, placebo controlled trials of infliximab given intravenously in a dose of $5 \mathrm{mg} / \mathrm{kg}$ of body weight on three occasions (weeks 0,2 , and 6) have demonstrated a quick therapeutic response and a statistically significant improvement in most patients with AS..$^{3-8}$ However, as in rheumatoid arthritis, treatment of AS must be continued because the disease activity returns a few weeks after infliximab is stopped. On the other hand, serious adverse events, including a predisposition to bacterial infections, reactivation of tuberculosis, and demyelinating diseases, are some of the disadvantages of infliximab therapy. ${ }^{6-8}$

This study was designed to investigate the efficacy and safety of long term infliximab therapy in patients with severe refractory AS.

\section{MATERIALS AND METHODS Study design}

Twenty five patients who fulfilled the modified New York criteria for AS were studied. ${ }^{9}$ The patients had had active disease for at least three months and were refractory to many drugs. The current treatment was NSAIDs, mainly indometacin, in all patients, while three patients were taking SSZ, two MTX, and four patients were also receiving prednisone ( $5 \mathrm{mg} /$ day). Despite the above treatment all patients had active disease. Therefore, we investigated whether infliximab would provide additional clinical benefit to these patients. The patients were given with intravenous infliximab $(5 \mathrm{mg} / \mathrm{kg}$ of body weight) at weeks 0, 2, 6, and every eight weeks thereafter, for 12 months. Patients were excluded from the study if they had (a) history or presence of malignant diseases; $(b)$ known liver or kidney abnormalities or history of viral hepatitis $\mathrm{B}$ and $\mathrm{C}$; (c) major complicating illnesses such as heart or lung diseases, blood dyscrasias, or amyloidosis; (d) positive tuberculin skin test using PPD/ RT23 (2 IU/0.1 ml), or an abnormal chest radiograph suggesting chronic infectious disease, granulomatous disease, or other pathological findings. The protocol was approved by the Institutional Scientific Board of the University Hospital of Ioannina, Greece. Patients were entered into the study after reading and signing an informed consent form.

\section{Clinical assessment}

Each patient underwent a complete physical examination before treatment at each visit until the end of the study and every two months thereafter. Clinical disease variables included: Bath Ankylosing Spondylitis Disease Activity Index (BASDAI), ${ }^{10}$ Bath Ankylosing Spondylitis Disease Functional Index (BASFI), ${ }^{11}$ patient's global assessment of pain (GAP) on a $100 \mathrm{~mm}$ visual analogue scale $(100 \mathrm{~mm}$ VAS), doctor's global assessment of disease activity ( $100 \mathrm{~mm}$ VAS), patient's global assessment of disease activity (100 mm VAS), Schober test $(\mathrm{cm})$, chest expansion $(\mathrm{cm})$, and weight $(\mathrm{kg})$. Laboratory disease variables included $\mathrm{C}$ reactive protein (CRP, $\mathrm{mg} / \mathrm{l})$, and erythrocyte sedimentation rate (ESR,

$\mathrm{mm} / \mathrm{lst} \mathrm{h}$ ) that were determined at each patient visit.

The primary end point was the reduction of the GAP by $>20 \%$. Secondary end points were the reduction of the pain by $50 \%$ and $70 \%$. Although not included in the original

\footnotetext{
Abbreviations: ANA, antinuclear antibodies; AS, ankylosing spondylitis; ASAS, AS Assessment Study Group; BASDAI, Bath Ankylosing Spondylitis Disease Activity Index; BASFI, Bath Ankylosing Spondylitis Functional Index; CRP, C reactive protein; DMARDs, disease modifying antirheumatic drugs; ESR, erythrocyte sedimentation rate; GAP, global assessment of pain; MTX, methotrexate; NSAIDs, nonsteroidal anti-inflammatory drugs; SSZ, sulfasalazine; VAS, visual analogue scale
} 


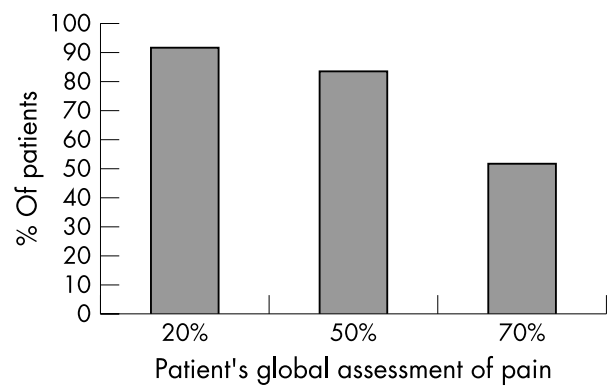

Figure 1 Improvement of patient's global assessment of pain.

design, criteria of improvement as defined by the BASDAI and AS Assessment Study Group (ASAS) were included in the analysis of efficacy. A response to treatment according to ASAS criteria requires improvement of at least $20 \%$ and absolute improvement of at least 10 units on a scale of 0-100 in three of the following four domains: (a) patient's global assessment of disease activity; (b) pain; (c) function (in this study the BASFI score); and (d) inflammation (in this study the mean of the morning stiffness related BASDAI, VAS scores) and the absence of deterioration by $20 \%$ and by $10 \%$ of units in the fourth domain. ${ }^{12}$

\section{Definitions}

The disease was defined as active if patients had BASDAI $\geqslant 30 / 100$ and $C R P \geqslant 10 \mathrm{mg} / \mathrm{l}$

\section{Monitoring}

A complete blood count with differential and platelets count, as well as serum values of liver enzymes, bilirubin, albumin, glucose, creatinine, and urine analysis were obtained before treatment and at each patient visit until the end of the study and every two months thereafter. Additionally, $2 \mathrm{ml}$ blood serum from patients, at each visit, was stored at $-20^{\circ} \mathrm{C}$ for measurement of the autoantibody profile.

\section{Statistics}

Statistical significance was estimated with Wilcoxon's test for pairs.

\section{RESULTS}

A total of 30 patients with AS were recruited. Five were excluded: 3 had a positive tuberculin skin test, 1 had congestive heart failure, and 1 had severe restrictive lung
Table 2 Adverse events recorded in patients with AS during treatment with infliximab

\begin{tabular}{|c|c|c|c|}
\hline Adverse events & $\begin{array}{l}\text { Number of } \\
\text { patients }\end{array}$ & $\begin{array}{l}\text { Number of } \\
\text { events }\end{array}$ & Outcome \\
\hline \multicolumn{4}{|l|}{ Infections } \\
\hline Common cold & 2 & 4 & Resolution \\
\hline Sore throat & 3 & 4 & Resolution \\
\hline \multicolumn{4}{|l|}{ Allergic reactions } \\
\hline Mild & 2 & 2 & Resolution \\
\hline Severe & 1 & 1 & Withdrawn \\
\hline \multicolumn{4}{|l|}{ Neurological } \\
\hline Paraesthesias & 1 & 1 & Resolution \\
\hline Total & 9 & 12 & \\
\hline
\end{tabular}

disease. Thus, 25 patients ( 24 male, 1 female) were enrolled. They had a mean age of 36.0 (10.5) years and a disease duration of 13.5 (8.5) years. Twenty two patients were HLAB27 positive. All patients had axial disease, only one had peripheral synovitis, and 10 patients had a history of anterior uveitis.

A reduction of the GAP of $>20 \%$ was achieved in 23 (92\%) patients.. Additionally, $21(84 \%)$ patients attained a reduction of $50 \%$ and $13(52 \%)$ a reduction of $70 \%$ (fig 1). This clinical improvement was noticed after the first three infusions and continued throughout the treatment. More specifically, after the third infusion at week 6, the results were significantly different from baseline as shown by reduction in the BASDAI, improvement of the BASFI, and decrease of disease activity according to the patient's and doctor's opinions (table 1). Twenty two $(84 \%)$ patients reached the BASDAI 20\% between weeks 6 and 52, and an improvement of BASDAI 50\% was reached in $15(60 \%)$ patients between weeks 6 and 52. Additionally, 22 (88\%) patients were responders according to the ASAS $20 \%$ criteria and $18(72 \%)$ achieved partial remission. Finally, an improvement of the Schober test and of body weight were noted. This clinical improvement was associated with a reduction of CRP and ESR (table 1). The clinical, functional, and laboratory improvement continued throughout the treatment and at week 52 a further statistically significant difference was noticed in the BASDAI, the BASFI, the disease activity according to the patient's and doctor's opinions, and the body weight (table 1).

The treatment was well tolerated with mild adverse events. Nine patients experienced adverse events, mainly infections

Table 1 Comparison of outcome measures before treatment, after six weeks and after 52 weeks of treatment with infliximab in patients with severe AS

\begin{tabular}{llcc}
\hline Variables & Week 0 & Week 6 & Week 52 \\
\hline BASDAl & $57.7(19.7)$ & $32.5(19.5)^{* * *}$ & $15.4(16.1)^{* * *}$ \\
BASFI & $58.3(22.2)$ & $33.3(16.2)^{* * *}$ & $16.3(14.0)^{* * *}$ \\
Patient's GAP (100 mm VAS) & $65.3(16.7)$ & $20.1(18.6)^{* * *}$ & $20.4(13.4)$ \\
Patient's global assessment of & $54.1(18.9)$ & $29.2(16.4)^{* * *}$ & $20.8(12.3)^{*}$ \\
disease activity (100 mm VAS) & & & \\
Doctor's global assessment of & $49.3(15.5)$ & $26.3(10.5)^{* * *}$ & $20.5(10.0)^{*}$ \\
disease activity (100 mm VAS) & $1.8(1.6)$ & $2.2(1.6)^{*}$ & $2.1(1.4)$ \\
Schober test (cm) & $1.8(0.8)$ & $2.3(1.3)$ & $2.3(1.3)$ \\
Chest expansion (cm) & $74.4(10.2)$ & $75.5(9.8)^{* *}$ & $78.3(9.6)^{* *}$ \\
Weight (kg) & $27.1(21.0)$ & $1.9(3.4)^{* * *}$ & $7.5(13.5)$ \\
CRP (mg/l) & $33.9(19.1)$ & $8.0(5.9)^{* * *}$ & $15.8(21.6)$ \\
ESR (mm/lst h) & &
\end{tabular}

The numbers in parentheses indicate the standard deviation.

BASDAI, Bath Ankylosing Spondylitis Disease Activity Index; BASFI, Bath Ankylosing Spondylitis Disease Functional Index; GAP, global assessment of pain; VAS, visual analogue scale; CRP, C reactive protein; ESR, erythrocyte sedimentation rate. ${ }^{*} \mathrm{p}<0.05 ;{ }^{* *} \mathrm{p}<0.01 ;{ }^{* * *} \mathrm{p}<0.001$ 
and allergic reactions. All these adverse events were resolved without sequelae. One patient withdrew owing to an immediate hypersensitivity reaction after the third infusion (table 2). One other patient with longstanding axial disease discontinued the study because of drug inefficacy after the fifth infusion. Finally, 6/25 patients developed positive antinuclear antibodies (ANA) with a titre ranging from $1 / 160$ to $1 / 640$ and all having a fine speckled pattern. No other antibodies were detected.

\section{DISCUSSION}

AS is a chronic inflammatory rheumatic disease which affects primarily the axial skeleton, leading to functional disability and premature death. ${ }^{13}$ Although there is no cure or treatment which shows proven efficacy in preventing disease progression, NSAIDs and physiotherapy have been the basis of AS treatment. ${ }^{2}$ Thus, there is a clear need for effective new treatments for this disease. Extensive rationale exists for the use of tumour necrosis factor $\alpha$ inhibition in AS, and a growing body of evidence demonstrates the clinical efficacy of this approach. Recent, short and long term, open label and randomised, double blind, placebo controlled trials showed that infliximab therapy in patients with active AS was well tolerated and improved global, peripheral, and axial disease quickly and significantly. ${ }^{3-6}{ }^{15}{ }^{16}$ However, the occurrence of serious adverse events ${ }^{6-8}$ in some patients necessitated the requirement for strict inclusion criteria and long term treatment and follow up. Thus, our study was designed to investigate the efficacy, tolerability, and safety of infliximab therapy in patients with active AS for a period of 12 months.

Ninety two per cent of patients in this study had a clinical response according to reduction of the GAP by $>20 \%, 84 \%$ attained a reduction of $50 \%$, and $52 \%$ of patients achieved a reduction of $70 \%$. The degree of improvement is particularly noteworthy in view of the inclusion of patients resistant to any previous treatment and with severe active disease. This clinical improvement was also associated with a reduction of the BASDAI, improvement of the BASFI and Schober test, and increased body weight. In addition, a reduction of CRP and ESR occurred in most patients.

Infusions of infliximab were generally well tolerated. Nine patients developed mild adverse events, mainly infections and allergic reactions and one paraesthesias. All these adverse reactions were resolved without sequelae. One patient had to stop infliximab therapy owing to an immediate hypersensitivity reaction after the third infusion. The absence of serious side effects in this study is probably attributed to the strict inclusion criteria used, the close follow up, and monitoring. Six of 25 patients developed positive ANA with a titre ranging from $1 / 160$ to $1 / 640$ and all having a fine speckled pattern. No antibodies to double stranded DNA or signs and symptoms of systemic lupus erythematosus were seen in these patients. A high frequency of ANA is found in rheumatoid arthritis, with $62 \%$ of patients who received infliximab plus MTX developing ANA, compared with $27 \%$ of patients treated with placebo plus MTX. An almost similar number of patients with spondyloarthropathies may develop positive ANA. ${ }^{17}$

One patient (male) discontinued the study because of drug inefficacy after the fifth effusion. He had a longstanding disease with severe kyphosis and complete axial ankylosis, also resistant to SSZ and to high doses of indometacin.

The results of this study strongly suggest that infliximab therapy is effective, safe, and well tolerated in patients with
AS treated for a period of 12 months. Our results are in agreement with the results of previous short and long term, double blind, placebo controlled trials in which infliximab was shown to be very effective..$^{3-8} 15{ }^{16}$ However, further, long term double blind, placebo controlled studies are needed to validate our results.

\section{Authors' affiliations}

TI Temekonidis, S N Nikas, D V Bougias, A N Georgiadis, P V Voulgari, A A Drosos, Division of Rheumatology, Department of Internal Medicine, Medical School, University of loannina, loannina, Greece

Y Alamanos, Department of Hygiene and Epidemiology, Medical School, University of loannina, Greece

Correspondence to: Professor A A Drosos, Department of Internal Medicine, Medical School, University of loannina, 45110, loannina, Greece; adrosos@cc.voi.gr

Accepted 29 July 2003

\section{REFERENCES}

1 Khan MA. Update on spondyloarthropathies. Ann Intern Med 2002; 136:896-907.

2 Scalapino KJ, Davis JC Jr. The treatment of ankylosing spondylitis. Clin Exp Med 2003;2:159-65.

3 Brandt J, Haibel H, Cornely D, Golder W, Gonzalez J, Reddig J, et al. Successful treatment of active ankylosing spondylitis with the anti-tumor necrosis factor alpha monoclonal antibody infliximab. Arthritis Rheum 2000;43:1346-52.

4 Stone M, Salonen D, Lax M, Payne U, Lapp V, Inman R. Clinical and imaging correlates of response to treatment with infliximab in patients with ankylosing spondylitis. J Rheumatol 2001;28:1605-14.

5 Van den Bosch F, Kruithof E, Baeten D, De Keyser F, Mielants H, Veys EM Effects of a loading dose regimen of three infusions of chimeric monoclonal antibody to tumor necrosis factor alpha (infliximab) in spondyloarthropathy: an open pilot study. Ann Rheum Dis 2000;59:428-33.

6 Van den Bosch F, Kruithof E, Baeten D, Herssens A, de Keyser F, Mielants H, et al. Randomized double-blind comparison of chimeric monoclonal antibody to tumor necrosis factor alpha (infliximab) versus placebo in active spondylarthropathy. Arthritis Rheum 2002;46:755-65.

7 Braun J, Brandt J, Listing J, Zink A, Alten R, Golder W, et al. Treatment of active ankylosing spondylitis with infliximab: a randomized controlled multicentre trial. Lancet 2002;359:1187-93.

8 Breban M, Vignon E, Claudepierre P, Devauchelle V, Wendling D, Lespessailles $\mathrm{E}$, et al. Efficacy of infliximab in refractory ankylosing spondylitis: results of a six-month open-label study. Rheumatology (Oxford) 2002;41:1280-5.

9 van der Linden S, Vankenburg HA, Cats A. Evaluation of diagnostic criteria for ankylosing spondylitis. A proposal for modification of the New York criteria. Arthritis Rheum 1984:27:361-8.

10 Calin A, Garrett S, Whitelock H, Kennedy LG, O'Hea J, Mallorie P, et al. A new approach to defining functional ability in ankylosing spondylitis: the development of the Bath ankylosing spondylitis functional index. J Rheumatol 1994;21:2281-5.

11 Garrett S, Jenkinson T, Kennedy LG, Whitelock H, Gaisford P, Calin A. A new approach to defining disease status in ankylosing spondylitis: the Bath ankylosing spondylitis disease activity index. J Rheumatol 1994;21:2286-91.

12 Anderson JJ, Baron G, van der Heijde D, Felson DT, Dougados M. Ankylosing spondylitis assessment group preliminary definition of short-term improvement in ankylosing spondylitis. Arthritis Rheum $2001 ; 44: 1876-86$.

13 Lehtinen K. Mortality and causes of death in 398 patients admitted to hospital with ankylosing spondylitis. Ann Rheum Dis 1993;52:174-6.

14 Khan MA, Khan MK, Kushner I. Survival among patients with ankylosing spondylitis: a life-table analysis. J Rheumatol 1981;8:86-90.

15 Maksymowych WP, Jhangri GS, Lambert RG, Mallon C, Buenviaje H, Pedrycz $E$, et al. Infliximab in ankylosing spondylitis: a prospective observational inception cohort analysis of efficacy and safety. J Rheumatol 2002;29:959-65.

16 Kruithof E, Van den Bosch F, Baeten D, Herssens A, De Keyser F, Mielants H, et al. Repeated infusions of infliximab, a chimeric anti-TNFalpha monoclonal antibody, in patients with active spondyloarthropathy: one year follow up. Ann Rheum Dis 2002;61:207-12.

17 De Rycke L, Kruithof E, Van Damme N, Hoffman IE, Van den Bossche N, $V$ an den Bosch $F$, et al. Antinuclear antibodies following infliximab treatment in patients with rheumatoid arthritis or spondylarthropathy. Arthritis Rheum 2003;48:1015-23. 